\title{
Genetic diversity, haplotypes and allele groups of Duffy binding protein (PkDBPall) of Plasmodium knowlesi clinical isolates from Peninsular Malaysia
}

Mun-Yik Fong ${ }^{1,2^{*}+}$, Yee-Ling Lau ${ }^{1,2}$, Phooi-Yee Chang ${ }^{1+}$ and Claudia Nisha Anthony ${ }^{1}$

\begin{abstract}
Background: The monkey malaria parasite Plasmodium knowlesi is now recognized as the fifth species of Plasmodium that can cause human malaria. Like the region II of the Duffy binding protein of P. vivax (PvDBPII), the region II of the $P$. knowlesi Duffy binding protein (PkDBPall) plays an essential role in the parasite's invasion into the host's erythrocyte. Numerous polymorphism studies have been carried out on PvDBPII, but none has been reported on PkDBPall. In this study, the genetic diversity, haplotyes and allele groups of PkDBPall of $P$. knowlesi clinical isolates from Peninsular Malaysia were investigated.

Methods: Blood samples from 20 knowlesi malaria patients and 2 wild monkeys (Macaca fascicularis) were used. These samples were collected between 2010 and 2012. The PkDBPall region of the isolates was amplified by PCR, cloned into Escherichia coli, and sequenced. The genetic diversity, natural selection and haplotypes of PkDBPall were analysed using MEGA5 and DnaSP ver. 5.10 .00 programmes.

Results: Fifty-three PkDBPall sequences from human infections and 6 from monkeys were obtained. Comparison at the nucleotide level against $P$. knowlesi strain $\mathrm{H}$ as reference sequence showed 52 synonymous and 76 nonsynonymous mutations. Analysis on the rate of these mutations indicated that PkDBPall was under purifying (negative) selection. At the amino acid level, 36 different PkDBPall haplotypes were identified. Twelve of the 20 human and 1 monkey blood samples had mixed haplotype infections. These haplotypes were clustered into 2 distinct allele groups. The majority of the haplotypes clustered into the large dominant group.

Conclusions: Our present study is the first to report the genetic diversity and natural selection of PkDBPall. Hence, the haplotypes described in this report can be considered as novel. Although a high level of genetic diversity was observed, the PkDBPall appeared to be under purifying selection. The distribution of the haplotypes was skewed, with one dominant major and one minor group. Future study should investigate PkDBPall of $P$. knowlesi from Borneo, which hitherto has recorded the highest number of human knowlesi malaria.
\end{abstract}

Keywords: Plasmodium knowlesi, Duffy binding protein, Diversity, Selection, Haplotypes, Allele groups

\section{Background}

Malaria is caused by blood protozoa of the genus Plasmodium. Historically, four species of Plasmodium are known to cause human malaria: Plasmodium falciparum, $P$. vivax, $P$. malariae, and $P$. ovale. However, about a decade ago, $P$. knowlesi, a malaria parasite of macaque monkeys, was

\footnotetext{
* Correspondence: fongmy@um.edu.my

${ }^{\dagger}$ Equal contributors

'Department of Parasitology, Faculty of Medicine, University of Malaya, 50603 Kuala Lumpur, Malaysia

${ }^{2}$ Tropical Infectious Diseases Research and Education Centre (TIDREC), Faculty of Medicine, University of Malaya, 50603 Kuala Lumpur, Malaysia
}

reported to cause a large number of human infections in Sarawak, Borneo Island [1]. Since then, human knowlesi malaria has been reported in other parts of Borneo Island, Peninsular Malaysia, and in many other countries in Southeast Asia [2]. Imported knowlesi malaria cases have been reported in European countries and Japan due to ecotourism programs to the forested areas of Southeast Asia. Now, P. knowlesi is recognised as the fifth species of Plasmodium that can cause human malaria.

Invasion of a malaria parasite into its host erythrocyte depends on the interaction between the parasite's 
protein and the corresponding receptor on the surface of the erythrocyte. Plasmodium vivax and P. knowlesi use the Duffy blood group antigen as a receptor to invade erythrocytes [3]. The Duffy binding proteins of $P$. vivax (PvDBP) and P. knowlesi (PkDBP) are located on their merozoites. PvDBP and PkDBP are members of the erythrocyte-binding protein family which also includes the P. falciparum EBA-175 [4]. PvDBP and PkDBP are large proteins and can be divided into seven regions (I-VII). Region II contains the critical motifs for binding to the erythrocyte Duffy antigen.

$\mathrm{PkDBP}$ is encoded by an $\alpha$-gene and therefore is more specifically known as PkDBP $\alpha$. This is to distinguish it from two other highly homologous proteins in $P$. knowlesi $-\beta$ and $\gamma$. Region II of the $\beta$ and $\gamma$ proteins have different binding specificities compared to PkDBP $\alpha$. Region II of the $\beta$ and $\gamma$ proteins binds to rhesus erythrocytes but does not bind to Duffy antigen of human erythrocytes [5].

PvDBP has been suggested to be an important vaccine candidate antigen against vivax malaria because it elicits strong immune responses in humans. Design of vaccine against vivax malaria must take into consideration the nature and genetic polymorphism of PvDBP. Region II of PvDBP (denoted as PvDBPII) in P. vivax isolates from different geographical regions such as Colombia, South Korea, Papua New Guinea, Thailand, Iran and Myanmar has been shown to be highly polymorphic, and numerous PvDBPII haplotypes and allele groups have been identified [6-11].

It has been observed that antibodies raised against PkDBPaII could inhibit $P$. knowlesi invasion of human and rhesus erythrocytes in vitro [12]. Therefore, like PvDBPII for vivax malaria, PkDBP $\alpha I$ may also be a candidate vaccine antigen against knowlesi malaria. Whilst many polymorphism studies on PvDBPII have been carried out, hitherto, none has been reported for PkDBPaII. In this report, we present our findings on genetic diversity, haplotyes and allele groups of PkDBPaII in P. knowlesi clinical isolates from Peninsular Malaysia.

\section{Methods}

\section{Blood samples}

Human blood samples used in this study were collected from 20 patients who were infected with Plasmodium knowlesi at the University of Malaya Medical Centre and several private clinics in Peninsular Malaysia. Two blood samples from P. knowlesi-infected wild monkeys (Macaca fascicularis) were provided by the Wildlife Department of Federal Territory, Peninsular Malaysia. These blood samples were collected between 2010 and 2012 from various states in Peninsular Malaysia (Table 1). Confirmation of P. knowlesi infection in all the samples was carried out by microscopic examination of Giemsa-stained thin and thick blood smears and polymerase chain reaction. Ethical
Table 1 Date and origin of human and monkey blood samples used in this study

\begin{tabular}{|c|c|c|}
\hline $\begin{array}{l}\text { Blood } \\
\text { sample }\end{array}$ & $\begin{array}{c}\text { Date } \\
\text { (Month, year) }\end{array}$ & $\begin{array}{c}\text { Origin } \\
\text { (State in Peninsular Malaysia) }\end{array}$ \\
\hline ANU & Feb 2012 & Kelantan \\
\hline$A Z L$ & Jun 2011 & Perak \\
\hline $\mathrm{CHO}$ & Oct 2010 & Pahang \\
\hline GAN & Oct 2011 & Selangor \\
\hline $\mathrm{HAl}$ & Feb 2012 & Kelantan \\
\hline HAN & Feb 2012 & Kelantan \\
\hline HEN & Feb 2012 & Kelantan \\
\hline IZA & Aug 2010 & Selangor \\
\hline$J U N$ & Feb 2012 & Kelantan \\
\hline MAD & Aug 2010 & Negeri Sembilan \\
\hline MAH & Aug 2011 & Selangor \\
\hline MEL & Feb 2012 & Kelantan \\
\hline NGO & Oct 2010 & Perak \\
\hline $\mathrm{OTH}$ & Feb 2012 & Kelantan \\
\hline RAU & Feb 2012 & Kelantan \\
\hline SUP & Feb 2012 & Kelantan \\
\hline SYA & Feb 2012 & Kelantan \\
\hline UM0001 & Jan 2012 & Selangor \\
\hline UM0002 & Feb 2012 & Kelantan \\
\hline UM0004 & Apr 2012 & Selangor \\
\hline Monkey566 & Oct 2010 & Negeri Sembilan \\
\hline Monkey569 & Oct 2010 & Pahang \\
\hline
\end{tabular}

approvals for the use of human and monkey blood samples in this study were granted by the University of Malaya Medical Centre Ethic Committee and (MEC No. 817.18) and the University of Malaya Animal Care and Use Committee (PAR/19/02/2013/AA[R]).

\section{Extraction of DNA}

Total DNA of the P. knowlesi was extracted from each blood sample using the QIAGEN Blood DNA Extraction kit (QIAGEN, Hilden, Germany). In each extraction, $100 \mu \mathrm{l}$ of blood was used. The extracted DNA was suspended in water to a final volume of $50 \mu \mathrm{l}$.

\section{PCR, cloning and sequencing of the PkDBPall}

The PkDBP $\alpha I$ was amplified by nested PCR using oligonucleotide primers Pk $\alpha$-DBP-F1: 5'-CGCATTTTGAA GGAATCCAC-3' and Pk $\alpha$-DBP-R1: 5'-TGCTAGACT TACCTTCACCT-3' for nest 1 . The primers for the nest 2 reaction were Pk $\alpha$-DBP-F: 5'-TCCTCAAAAGGCGG TGACCATCC-3' and Pk $\alpha$-DBP-R: 5'-ACTGGCTGCC TTAGATTCAACACCA-3'. Cycling conditions for nest 1 were as follows: $95^{\circ} \mathrm{C}$ for 4 mins, 30 cycles at $95^{\circ} \mathrm{C}$ for 30 secs, $48^{\circ} \mathrm{C}$ for 30 secs, and $72^{\circ} \mathrm{C}$ for 90 secs, followed 


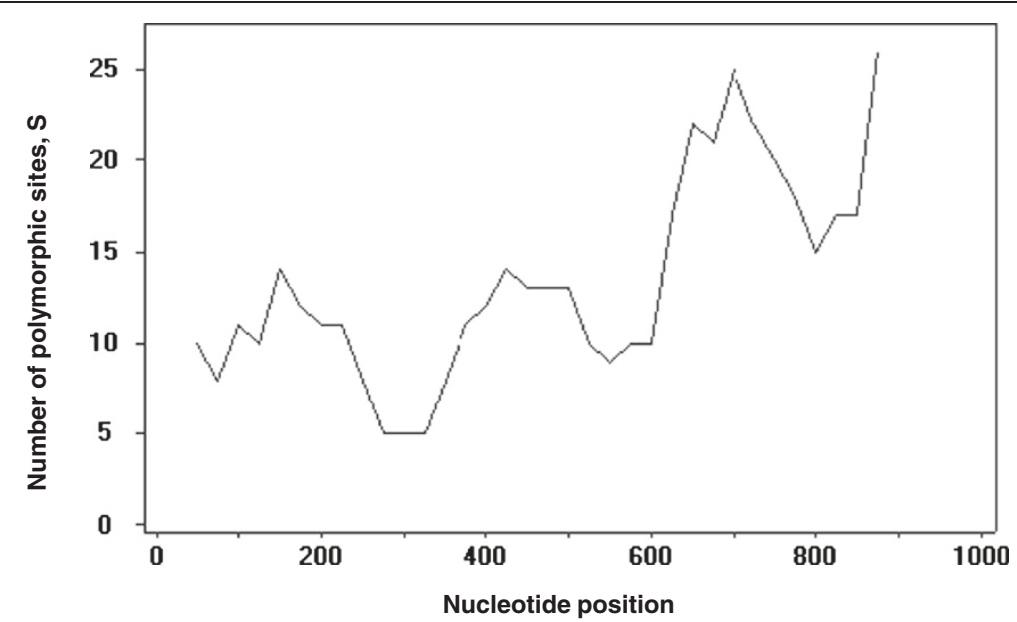

Figure 1 Nucleotide polymorphism in the PkDBPall of $P$. knowlesi. Sliding window plot of number of polymorphic sites (S) along the PkDBPall, generated by using DnaSP ver. 5.10 .00 with a window length of $100 \mathrm{bp}$ and step size of $25 \mathrm{bp}$.

by a $10 \mathrm{~min}$ extension at $72^{\circ} \mathrm{C}$. The amplification for nest 2 was performed using the following cycling profile: $95^{\circ} \mathrm{C}$ for 4 mins, 30 cycles at $95^{\circ} \mathrm{C}$ for 30 secs, $56^{\circ} \mathrm{C}$ for $30 \mathrm{secs}$, and $72^{\circ} \mathrm{C}$ for $90 \mathrm{secs}$, followed by a $10 \mathrm{~min}$ extension at $72^{\circ} \mathrm{C}$. The PCR product with an expected size of $1053 \mathrm{bp}$ was analyzed on a 1\% agarose gel.

\section{Purification of PCR products and DNA cloning}

PCR products were purified by QIAquick PCR purification Kit (QIAGEN, Hilden, Germany) following the manufacturer's instructions. The purified PCR products were then ligated into cloning vector pGEM-T ${ }^{\bullet}$ (Promega Corp., USA) and transformed into Escherichia coli

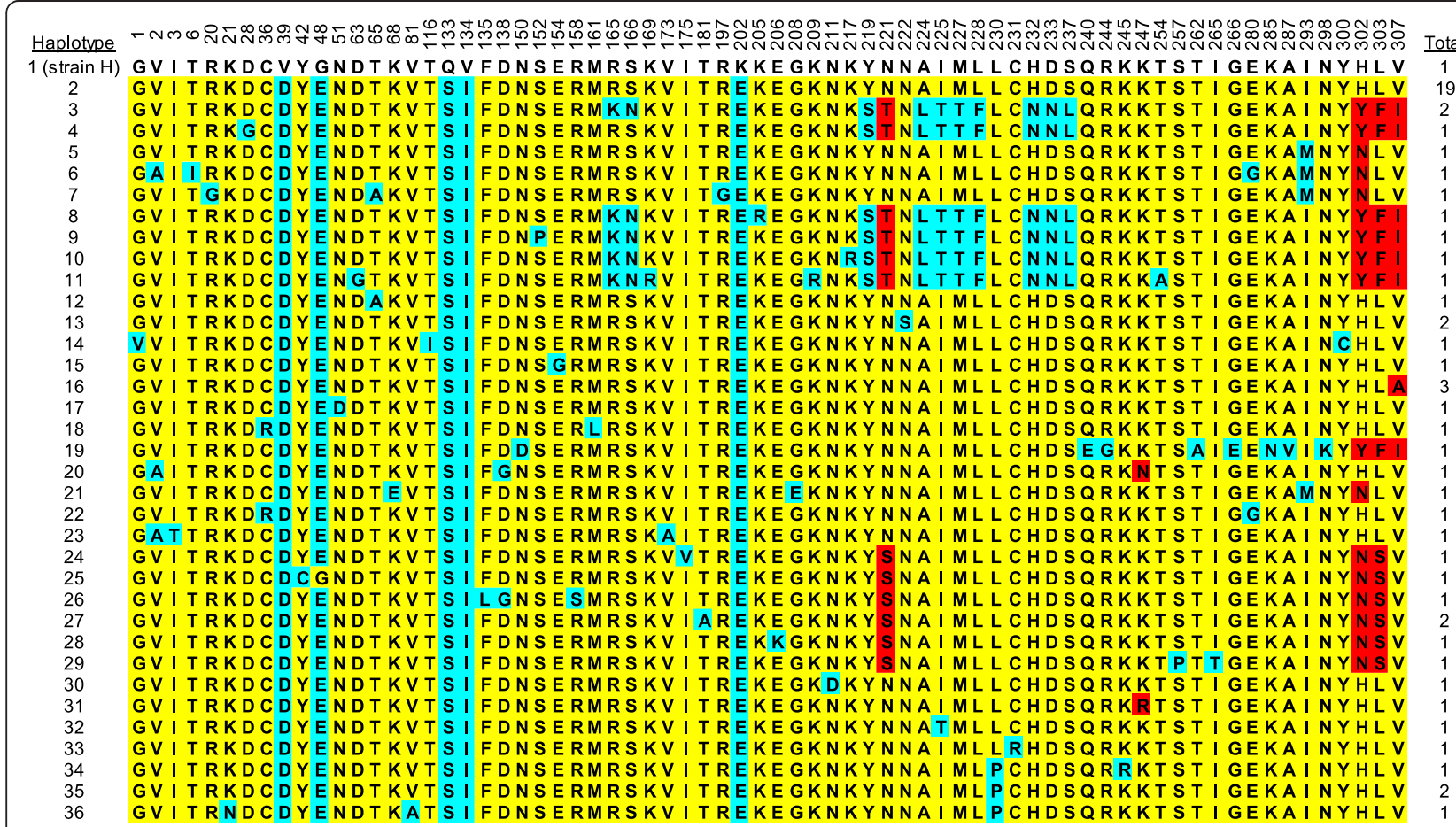

Figure 2 Amino acid sequence polymorphism in PkDBPall. Polymorphic amino acid residues are listed for each haplotype. Amino acid residues identical to those of the reference sequence, strain $\mathrm{H}$ (haplotype 1), are marked in yellow. Monomorphic and dimorphic amino acid changes are marked in blue and red, respectively. Total number of sequences for each haplotype is listed in the right panel. 
TOP10F'. Plasmids of recombinant clones harbouring the PkDBP $\alpha I$ fragment were sent to a commercial laboratory for DNA sequencing. To detect the possibility of multiple haplotypes infecting a patient or monkey, plasmids from 4-6 recombinant clones from each transformation mixture were sequenced.

\section{Analysis of PkDBPall sequences}

Alignment of 60 sequences of PkDBPaII [53 of human origin, 6 of monkey origin, 1 reference strain (strain $H$, GenBank Accession No. M90466)] were performed using CLUSTAL-Omega programme which was available on-line (http://www.ebi.ac.uk/Tools/msa/clustalo). Both nucleotide and the deduced amino acid sequences were aligned and analysed. Phylogenetic tree was constructed using the Neighbour Joining method described in MEGA5 [13]. In constructing the phylogenetic tree, bootstrap replicates of 1000 were used to test the robustness of the tree.

\section{PkDBPall sequence polymorphism analysis}

DnaSP ver. 5.10.00 [14] was used to perform polymorphism analysis on the $60 \mathrm{PkDBP} \alpha \mathrm{II}$ sequences. Information such as the number of segregating sites (S), haplotype diversity $(\mathrm{Hd})$, nucleotide diversity $(\pi)$, and average number of pairwise nucleotide differences within the population $(\mathrm{K})$ were generated. The $\pi$ was also calculated on a sliding window of 100 bases, with a step size of 25 bp to estimate the stepwise diversity across PkDBP $\alpha$ II. The rates of synonymous $(K \mathrm{~s})$ and non-synonymous $(K \mathrm{n})$ substitutions were estimated and compared by the Z-test $(\mathrm{P}<0.05)$ in MEGA5 using the Nei and Gojobori's method [15] with the Jukes and Cantor correction. In the case of purifying (negative) selection, mutations are usually not advantageous so that $K \mathrm{n}$ will be less than $K \mathrm{~s}(\mathrm{Kn} / K \mathrm{~s}<1)$. However, in positive selection, non-synonymous mutations can be advantageous and $K \mathrm{n}$ will exceed $K \mathrm{~s}(K \mathrm{n} / K \mathrm{~s}>1)$. For testing the neutral theory of evolution, Tajima's D [16] and Fu and Li's D and F [17] tests was carried out using DnaSP 5.10.00. In the Fu and Li's tests, P. vivax PvDBPII (GenBank Accession No. M90466) was used as outgroup.

\section{Results}

Nested PCR amplification on the human and monkey blood samples isolates produced DNA fragments of 1053 base pairs. The sequence of each fragment was trimmed to 921 bp, based on the PkDBPoII region identified by Singh et al. [18]. This trimmed sequence encoded an amino acid sequence of 307 in length. A final total of 59 sequences (GenBank Accession No. KC597079 - KC597137) were obtained.

DNA sequence analyses were conducted to determine nucleotide diversity and genetic differentiation. The average number of pairwise nucleotide differences $(K)$ for the
PkDBPaII was 11.736. The overall haplotype diversity $(\mathrm{Hd})$ and nucleotide diversity $(\pi)$ for the $60 \mathrm{PkDBP} \alpha \mathrm{II}$ sequences were $0.986 \pm 0.008$ and $0.013 \pm 0.002$, respectively. Detailed analysis of $\pi$, with a sliding window plot (window length $100 \mathrm{bp}$, step size $25 \mathrm{bp}$ ), revealed diversity ranged from 0.003 to 0.034 . The highest peak of nucleotide diversity was within nucleotide positions $600-750$, whereas the most conserved region was within nucleotide positions 260-360 (Figure 1).

Analysis and comparison at the nucleotide level against $P$. knowlesi strain $\mathrm{H}$ as reference sequence showed mutations at 128 positions among the Peninsular Malaysia isolates. Fifty-two of these mutations were synonymous and 76 were nonsynonymous. To determine whether natural selection contributed to the diversity in the PkDBPoII, the rate of nonsynonymous $(\mathrm{Kn})$ to synonymous mutations $(K \mathrm{~s})$ was estimated. Kn $(0.00952)$ was found lower than Ks $(0.00278)$ and the $K \mathrm{n} / K \mathrm{~s}$ ratio was 0.347 , suggesting that purifying (negative) selection may be occurring in the PkDBPaII. Similarly, the $\mathrm{Z}$ test $(K \mathrm{~s}>K \mathrm{n} ; \mathrm{P}<0.05)$ also indicated purifying selection on PkDBPaII. In the tests of departure of neutrality of selection, the Tajima's D statistics was $-2.085(P<0.05)$, indicating expansion in

Table 2 PkDBPall haplotypes detected in the human and monkey blood samples

\begin{tabular}{cc}
\hline Blood sample & Haplotype \\
\hline ANU & $\mathrm{H} 2$ \\
AZL & $\mathrm{H} 9, \mathrm{H} 10, \mathrm{H} 11$ \\
CHO & $\mathrm{H} 3, \mathrm{H} 8$ \\
GAN & $\mathrm{H} 5, \mathrm{H} 6, \mathrm{H} 7$ \\
HAl & $\mathrm{H} 18, \mathrm{H} 19$ \\
HAN & $\mathrm{H} 2$ \\
HEN & $\mathrm{H} 2$ \\
IZA & $\mathrm{H} 2, \mathrm{H} 3, \mathrm{H} 4$ \\
JUN & $\mathrm{H} 15$ \\
MAD & $\mathrm{H} 24, \mathrm{H} 25, \mathrm{H} 26, \mathrm{H} 27, \mathrm{H} 28, \mathrm{H} 29$ \\
MAH & $\mathrm{H} 2, \mathrm{H} 33$ \\
MEL & $\mathrm{H} 12, \mathrm{H} 13, \mathrm{H} 14$ \\
NGO & $\mathrm{H} 2$ \\
OTH & $\mathrm{H} 2, \mathrm{H} 16$ \\
RAU & $\mathrm{H} 2, \mathrm{H} 30, \mathrm{H} 31$ \\
SUP & $\mathrm{H} 17$ \\
SYA & $\mathrm{H} 2, \mathrm{H} 20$ \\
UM0001 & $\mathrm{H} 21$ \\
UM0002 & $\mathrm{H} 2, \mathrm{H} 22, \mathrm{H} 23$ \\
UM0004 & $\mathrm{H} 32$ \\
Monkey566 & $\mathrm{H} 2$ \\
Monkey569 & $\mathrm{H} 34, \mathrm{H} 35, \mathrm{H} 36$ \\
\hline
\end{tabular}


population size and/or purifying selection. This is further supported by the $\mathrm{Fu}$ and Li's $\mathrm{D}$ and $\mathrm{F}$ tests statistics $(-3.772$ and -3.756 , respectively; $\mathrm{P}<0.05)$.

Comparison at the amino acid level revealed high polymorphism across the entire PkDBPaII of the isolates (Figure 2). Among the 70 polymorphic sites, 66 showed monomorphic mutation (changed into one amino acidtype) and 4 showed dimorphic mutation [changed into two amino acid types: $221(\mathrm{Q}, \mathrm{T}), 302(\mathrm{~N}, \mathrm{Y}), 303$ (F, S), 307 (A, I)]. The amino acid sequences could be categorised into 36 different haplotypes (H1-H36) with haplotype 2 having the highest frequency (19/60). Twelve of the 20 human and 1 monkey blood samples had mixed haplotype infections (Table 2). Phylogenetic tree analysis revealed that the haplotypes could be clustered into 2 main allele groups (Figure 3).

\section{Discussion}

The DBP of P. vivax and P. knowlesi play an essential role in erythrocyte invasion of the parasites by mediating irreversible binding with its corresponding receptor, the Duffy protein receptor for chemokines (DARC) on the surface of erythrocytes [19]. The DBP elicits strong immune responses in humans and therefore has been suggested to be an important vaccine candidate antigen $[12,20]$. The critical erythrocyte-binding motif of DBP has been identified to be located in region II of the protein. The P. vivax PvDBP has been observed to have a high degree of genetic polymorphism, and most of the polymorphism is located in region II. Although the cysteine and some hydrophobic amino acid residues in PvDBPII are conserved in $P$. vivax populations from different geographic regions, but the remaining amino acid

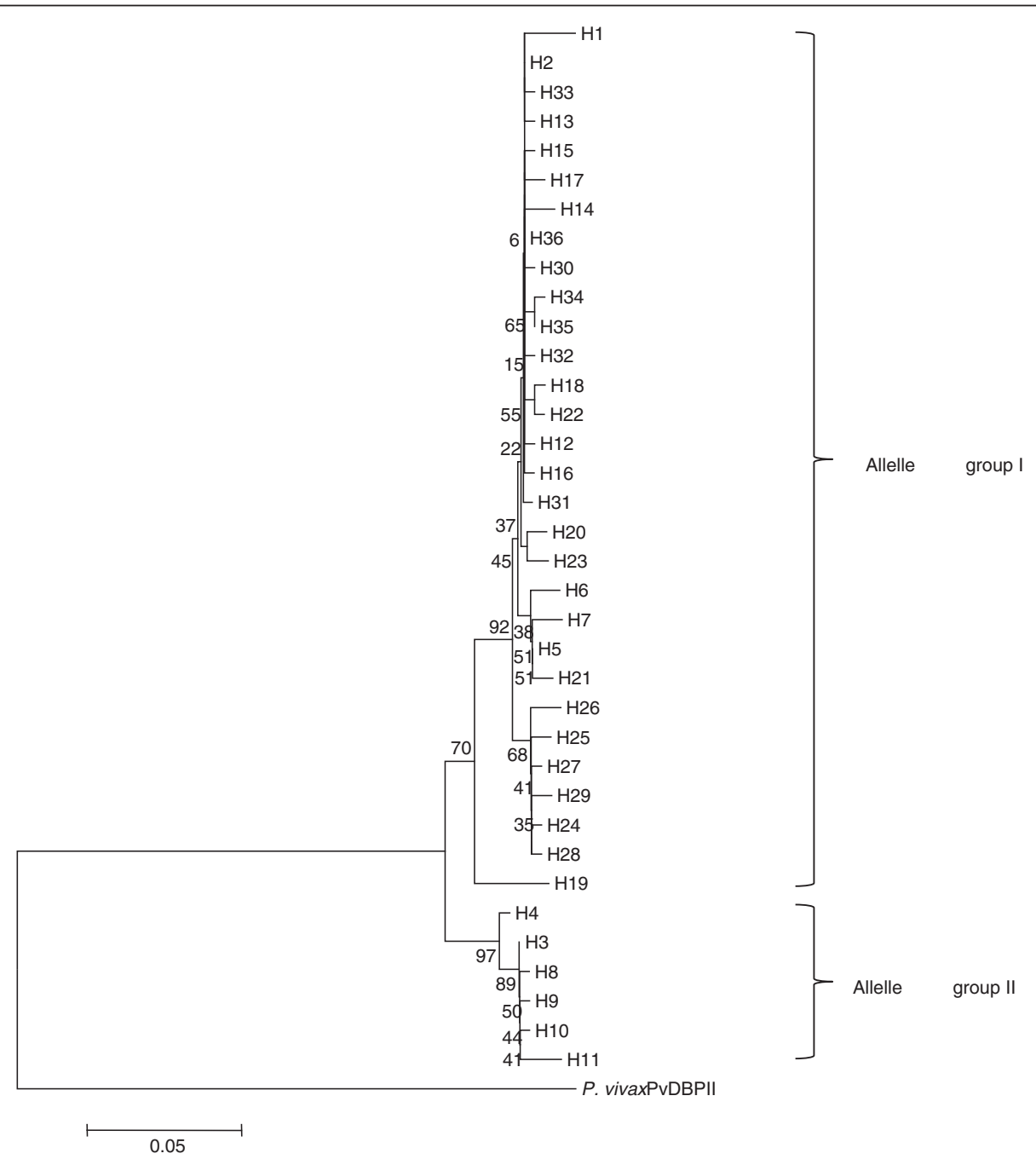

Figure 3 Phylogenetic tree of PkDBPall haplotypes. Neighbour-Joining method was used to construct the tree, which contains 36 haplotypes. Plasmodium vivax PvDBPII was used as outgroup. Numbers at nodes indicate percentage support of 1000 bootstrap replicates. 
residues are highly polymorphic [6-11,21-24]. It has further been revealed that PvDBPII undergoes positive natural pressure which results in allelic variation as a mechanism for immune evasion. On the other hand, despite the emerging importance of $P$. knowlesi as a human pathogen, no study has thus far been carried out on PkDBPaII. Our present study is the first to report the diversity and natural selection of PkDBP $\alpha I I$.

The PkDBPoII analysed in this study is based on the region defined by Singh et al. [18] using structural biology analysis. In their analysis, twelve $C$ residues (positions 16, 29, 36, 45, 99, 176, 214, 226, 231, 235, 304, 306), which form six disulphide bridges, have been suggested to be involved in the folding of PkDBPaII for interaction with DARC. Multiple alignment of the 60 PkDBPoII amino acid sequences (Additional file 1) in our study revealed that these 12 residues were highly conserved. Apart from these conserved $\mathrm{C}$ residues, the Y94, N95, K96, R103, L168 and I175 residues are required for recognition of DARC on human erythrocytes [18]. Again, our multiple sequence alignment showed high conservation of these residues in the PkDBPaII. In fact, Y94, N95, K96 and R103 fall within the most conserved region in the PkDBPaII (nucleotide positions $260-360$ in the gene, Figure 1).

The PkDBPoII $(\mathrm{K}=11.736$; $\mathrm{Hd}=0.986 ; \pi=0.01274)$ in Peninsular Malaysia seemed to be more diverse than P. vivax PvDBPII in some neighbour countries, such as Myanmar ( $\mathrm{K}=7.851 ; \mathrm{Hd}=0.875 ; \pi=0.00790)$, Korea ( $\mathrm{K}=$ 2.878; $\mathrm{Hd}=0.775 ; \pi=0.00299)$ and Sri Lanka $(\mathrm{Hd}=0.922$; $\pi=0.00982)[7,11,25]$. Generally, high levels of genetic diversity in malaria parasite surface antigens are attributed to positive natural selection, for example, by the host immune system [26]. Positive selection has been reported in PvDBPII of isolates in Myanmar, Korea, Sri Lanka and Thailand $[7,9,11,25]$. On the contrary, the PkDBP $\alpha I$ in Peninsular Malaysia was found to be under purifying (negative) selection. The reason for this finding is unclear, but may be associated with the host of the parasite. For example, it has been reported that the rhoptry-associated protein 1 (RAP-1) antigen of non-human primate malarial parasites (P. knowlesi, P. cynomolgi, P. inui and P. fieldi) showed evidence for negative selection, which was not found in two human malarial parasites (P. falciparum, $P$. vivax) [27]. Another possible reason for the purifying selection on PkDBPaII is population expansion of P. knowlesi, as evident by the Tajima's D statistics. In Peninsular Malaysia, deforestation in many areas has increased monkey and forest dwelling Anopheles vector contact to human. The expansion of monkey and vector populations and their ecological niches into human habitation may therefore result in the population expansion of P. knowlesi [28].

Phylogenetic studies on $P$. vivax isolates based on PvDBPII revealed the occurrence of multiple haplotypes in a geographical location, and these haplotypes could be categorized into several allele groups. For example, 25 haplotypes from Thailand were organized into 5 groups [9]. In Papua New Guinea, 27 haplotypes clustered into 3 dominant groups [9], whereas in Korea, 13 haplotypes were clustered into 3 groups [7]. Our study revealed the occurrence of 2 distinct allele groups of PkDBP $\alpha I$ in Peninsular Malaysia (Figure 3). Interestingly, allele group I was more dominant as it contained the majority (30/36) of the haplotypes. The minor allele group II had only 6 haplotypes. Two monkey blood samples were included in this study but all haplotypes from the monkeys were grouped in allele group I. The reference strain H, which was isolated in 1965 in Peninsular Malaysia from the first reported case of human P. knowlesi infection [29], was also grouped in allele group I. This shows that despite temporal separation of almost 50 years between strain $\mathrm{H}$ and the recent isolates of this study, no major genetic differences had occurred in the PkDBPoII.

\section{Conclusions}

Our present study is the first to report the genetic diversity and natural selection of PkDBP $\alpha$ II. Hence, the haplotypes described in this report can be considered as novel. Although a high level of genetic diversity was observed, the PkDBPaII appeared to be under purifying (negative) selection. Two allele groups of haplotype were obtained. However, the distribution was skewed, in which majority of the haplotypes clustered in a large dominant group. Our study was carried out on Peninsular Malaysia isolates only. Therefore, future study should investigate PkDBPaII of $P$. knowlesi from Borneo, which hitherto has recorded the highest number of human knowlesi malaria.

\section{Additional file}

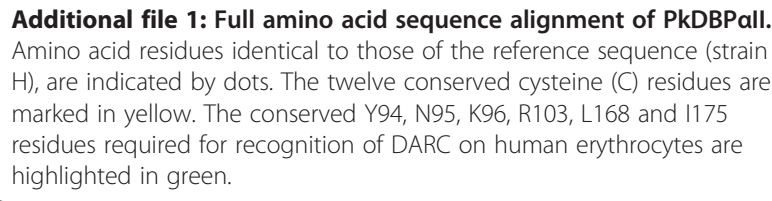

Additional file 1: Full amino acid sequence alignment of PkDBPall. Amino acid residues identical to those of the reference sequence (strain $\mathrm{H})$, are indicated by dots. The twelve conserved cysteine $(C)$ residues are marked in yellow. The conserved Y94, N95, K96, R103, L168 and I175 residues required for recognition of DARC on human erythrocytes are highlighted in green.

\section{Competing interests}

The authors declare that they have no competing interests.

\section{Authors' contributions}

MYF and YLL designed the study and supervised the study process. PYC performed all the experiments and analysed the sequence data. MYF and CNA performed sequence and phylogenetic analyses. MYF, YLL and CNA wrote the manuscript. All authors read and approved the final manuscript.

\section{Acknowledgements}

This study was supported by the UM High Impact Research Grant UM-MOHE UM.C/625/1/HIR/MOHE/MED/09 from the Ministry of Higher Education Malaysia, and the UM Postgraduate Student Research Grant (PV044/2012A). 
We thank the Department of Parasitology Diagnostic Laboratory, Faculty of Medicine, University of Malaya and University of Malaya Medical Centre for providing patient blood samples. We also thank the Department of Wildlife and Nature Parks (DWNP) Malaysia for providing monkey blood samples.

Received: 10 December 2013 Accepted: 31 March 2014 Published: 3 April 2014

\section{References}

1. Singh B, Kim Sung L, Matusop A, Radhakrishnan A, Shamsul SS, Cox-Singh J, Thomas A, Conway DJ: A large focus of naturally acquired Plasmodium knowlesi infections in human beings. Lancet 2004, 363:1017-1024.

2. Galinski MR, Barnwell JW: Monkey malaria kills four humans. Trends Parasitol 2009, 25:200-204.

3. Gaur D, Mayer DC, Miller LH: Parasite ligand-host receptor interactions during invasion of erythrocytes by Plasmodium merozoites. Int $\mathrm{J}$ Parasitol 2004, 34:1413-1429.

4. Adams JH, Sim BKL, Dolan SA, Fang X, Kaslow DC, Miller LH: A family of erythrocyte binding proteins of malaria parasites. Proc Natl Acad Sci U S A 1992, 89:7085-7089.

5. Chitnis $C E$, Miller $L H$ : Identification of the erythrocyte binding domains of Plasmodium vivax and Plasmodium knowlesi proteins involved in erythrocyte invasion. J Exp Med 1994, 180:497-506.

6. Ampudia E, Patarroyo MA, Patarroyo ME, Murillo LA: Genetic polymorphism of the Duffy receptor binding domain of Plasmodium vivax in Colombian wild isolates. Mol Biochem Parasitol 1996, 78:269-272.

7. Ju HL, Kang JM, Moon SU, Bahk YY, Cho PY, Sohn WM, Park YK, Park JW, Kim TS, Na BK: Genetic diversity and natural selection of Duffy binding protein of Plasmodium vivax Korean isolates. Acta Trop 2013, 125:67-74.

8. Xainli J, Adams JH, King CL: The erythrocyte binding motif of Plasmodium vivax Duffy binding protein is highly polymorphic and functionally conserved in isolates from Papua New Guinea. Mol Biochem Parasitol 2000, 111:253-260

9. Gosi P, Khusmith S, Khalambaheti T, Lanar DE, Schaecher KE, Fukuda MM, Miller SR: Polymorphism patterns in Duffy-binding protein among Thai Plasmodium vivax isolates. Malar J 2008, 7:112.

10. Babaeekho L, Zakeri S, Djadid ND: Genetic mapping of the Duffy binding protein (DBP) ligand domain of Plasmodium vivax from unstable malaria region in the Middle East. Am J Trop Med Hyg 2009, 80:112-118.

11. Ju HL, Kang JM, Moon SU, Kim JY, Lee HW, Lin K, Sohn WM, Lee JS, Kim TS, Na BK: Genetic polymorphism and natural selection of Duffy binding protein of Plasmodium vivax Myanmar isolates. Malar J 2012, 11:60.

12. Singh AP, Puri SK, Chitnis CE: Antibodies raised against receptor-binding domain of Plasmodium knowlesi Duffy binding protein inhibit erythrocyte invasion. Mol Biochem Parasitol 2002, 121:21-31.

13. Tamura K, Peterson D, Peterson N, Stecher G, Nei M, Kumar S: MEGA5: Molecular evolutionary genetics analysis using maximum likelihood, evolutionary distance, and maximum parsimony methods. Mol Biol Evol 2011, 28:2731-2739.

14. Librado P, Rozas J: DnaSP v5: a software for comprehensive analysis of DNA polymorphism data. Bioinformatics 2009, 25:1451-1452.

15. Nei $\mathrm{M}$, Gojobori T: Simple methods for estimating the numbers of synonymous and nonsynonymous nucleotide substitutions. Mol Biol Evol 1986, 3:418-426

16. Tajima F: Statistical method for testing the neutral mutation hypothesis by DNA polymorphism. Genetics 1989, 123:585-595.

17. Fu YX, Li WH: Statistical tests of neutrality of mutations. Genetics 1993, 133:693-709.

18. Singh SK, Hora R, Belrhali H, Chitnis CE, Sharma A: Structural basis for Duffy recognition by the malaria parasite Duffy-binding-like domain. Nature 2006, 439:741-744.

19. Horuk R, Chitnis CE, Darbonne WC, Colby TJ, Rybicki A, Hadley TJ, Miller LH: A receptor for the malaria parasite Plasmodium vivax: the erythrocyte chemokine receptor. Science 1993, 261:1182-1184.

20. King CL, Michon P, Shakri AR, Marcotty A, Stanisic D, Zimmerman PA, Cole-Tobian JL, Mueller I, Chitnis CE: Naturally acquired Duffy-binding protein-specific binding inhibitory antibodies confer protection from blood-stage Plasmodium vivax infection. Proc Natl Acad Sci U S A 2008, 105:8363-8368.
21. Kho WG, Chung JY, Sim EJ, Kim DW, Chung WC: Analysis of polymorphic regions of Plasmodium vivax Duffy binding protein of Korean isolates. Korean J Parasitol 2001, 39:143-150.

22. Cole-Tobian J, King CL: Diversity and natural selection in Plasmodium vivax Duffy binding protein gene. Mol Biochem Parasitol 2003, 127:121-132.

23. Sousa TN, Cerávolo IP, Fernandes Fontes CJ, Couto A, Carvalho LH, Brito CF: The pattern of major polymorphisms in the Duffy binding protein ligand domain among Plasmodium vivax isolates from the Brazilian Amazon area. Mol Biochem Parasitol 2006, 146:251-254.

24. Sousa TN, Tarazona-Santos EM, Wilson DJ, Madureira AP, Falcão PR, Fontes CJ, Gil LH, Ferreira MU, Carvalho LH, Brito CF: Genetic variability and natural selection at the ligand domain of the Duffy binding protein in Brazilian Plasmodium vivax populations. Malar J 2010, 9:334.

25. Premaratne PH, Aravinda BR, Escalante AA, Udagama PV: Genetic diversity of Plasmodium vivax Duffy Binding Protein II (PvDBPII) under unstable transmission and low intensity malaria in Sri Lanka. Infect Genet Evol 2011, 11:1327-1339.

26. Escalante AA, Cornejo OE, Rojas A, Udhayakumar V, Lal AA: Assessing the effect of natural selection in malaria parasites. Trends Parasitol 2004, 20:388-395.

27. Pacheco MA, Ryan EM, Poe AC, Basco L, Udhayakumar V, Collins WE, Escalante AA: Evidence for negative selection on the gene encoding rhoptry-associated protein 1 (RAP-1) in Plasmodium spp. Infect Genet Evol 2010, 10:655-661.

28. Vythilingam I: Plasmodium knowlesi in humans: a review on the role of its vectors in Malaysia. Trop Biomed 2010, 27:1-12.

29. Chin W, Contacos PG, Coatney GR, Kimball HR: A naturally acquired quotidian-type malaria in man transferable to monkeys. Science 1965, 149:865.

doi:10.1186/1756-3305-7-161

Cite this article as: Fong et al:: Genetic diversity, haplotypes and allele groups of Duffy binding protein (PkDBPall) of Plasmodium knowlesi clinical isolates from Peninsular Malaysia. Parasites \& Vectors 2014 7:161.

\section{Submit your next manuscript to BioMed Central and take full advantage of:}

- Convenient online submission

- Thorough peer review

- No space constraints or color figure charges

- Immediate publication on acceptance

- Inclusion in PubMed, CAS, Scopus and Google Scholar

- Research which is freely available for redistribution 